\title{
Comparative study of vectis versus manual method for extraction of fetal head during lower segment cesarean section
}

\author{
Priyanka HK*, Madhavi Yeddala, Vimala KR, Shailaja N., Bhat BS, Krishna L.
}

\begin{abstract}
Department of Obstetrics and Gynaecology, P.E.S. Institute of Medical Sciences and Research, Kuppam, Andhra
\end{abstract} Pradesh, India

Received: 08 December 2016

Accepted: 13 December 2016

*Correspondence:

Dr. Priyanka HK,

E-mail: priyanka.hk293@gmail.com

Copyright: (c) the author(s), publisher and licensee Medip Academy. This is an open-access article distributed under the terms of the Creative Commons Attribution Non-Commercial License, which permits unrestricted non-commercial use, distribution, and reproduction in any medium, provided the original work is properly cited.

\begin{abstract}
Background: Delivery of fetal head through uterine incision is often the major technical problem during low transverse cesarean section when the presenting part is unengaged. Techniques to deliver head under special circumstances are traumatic to both mother and fetus. This study aims to establish the role of vectis in extraction of fetal head during lower segment cesarean section (LSCS) and to assess associated difficulties or untoward effects of use of vectis over manual method.

Methods: The study was undertaken in PESIMSR, Kuppam, Andhra Pradesh over two years. Vectis was used in extraction of fetal head in LSCS in 100 cases of full term pregnancy and maternal and neonatal outcomes were compared with 100 cases of manual extraction.

Results: Incision-delivery time interval was similar in both vectis and manual extraction method (p value of 0.390). Vectis group did not require any fundal pressure for extraction of head where as $100 \%$ of women in manual extraction group required fundal pressure ( $p$ value: $<0.001$ ) which is statistically significant. The length of abdominal incision for majority of cases in vectis group was smaller and statistically significant compared to manual extraction group ( $\mathrm{p}$ value of 0.001 ). Neonatal outcomes were similar in both the groups.

Conclusions: As per our study, usage of vectis has shown significant advantage in reducing maternal discomfort caused due to fundal pressure and length of abdominal incision required, with negligible difference in neonatal and other maternal outcomes in comparison to manual method of extraction.
\end{abstract}

Keywords: Fundal pressure, Manual extraction, Maternal outcome, Neonatal outcome, Vectis

\section{INTRODUCTION}

Cold examination will reveal that delivery of head by hand is predominantly, virtually exclusively and universally employed by majority of obstetric surgeons in billions of clinical intraoperative situations over a time period measured by centuries. This has not changed. The success of the hand to deliver the head, with ease, with allied maneuvers by the other hand or others hand or hands, or with difficulty, is not challenged as a fact.
However, this needs to be taken up for examination, assessment and alternatives if found reasonable, suitable and advantageous. ${ }^{1}$

Current scenario and basic considerations are- the hand is used to deliver the fore coming head including vertex, face brow presentations. Some modification of technique in each and individual case is employed. This is usually instinctive, or as a hurried and harried response to difficulty rather than by any designed action plan. It is at this time that the assistant(s), anaesthetist and/or theatre staff lends their solicited or unsolicited efforts bordering 
on bravado. Attention to verification of presentation, position, station, flexion status of the trapped baby is absent, scant or cursory. ${ }^{2}$ The allied maneuvers are various such as one's own hand around the fundus facilitating the other hand to guide the head, out of the uterine incision. At times bimanual fundal pressure from the anaesthetist is a vigorous adjunct for some. ${ }^{2,3}$

The use of single blade of forceps, if available, is sometimes made. The purpose is to lever out the transverse/oblique head. However, a blade with the correct curve and a fixed handle is impossible to introduce owing to contact of the handle with the anterior abdominal wall, which is thrown forwards by the pregnant uterus. One more instrument used in cesarean section to extract fetal head is Barton's forceps which are useful for cesarean delivery when the fetal head is high in a transverse position, particularly when the operative field provides limited access to the head because of a low transverse incision and maternal obesity. ${ }^{4}$

In some cases, ventouse/vacuum extractor can be applied successfully but it has the disadvantage of causing more neonatal injuries such as cephalhematoma due to incorrect application. Due to the above-mentioned complications, Murless vectis, a specially designed variant, is sometimes employed. The instrument, which is fashioned like a forceps blade, curves round the fetal head just above the symphysis pubis and gently lifts the head out of the uterus.

Our study was undertaken to establish the role of vectis in extraction of fetal head in LSCS and to assess associated difficulties or untoward effects of use of vectis. This study aimed at critical and clinical evaluation of vectis over manual method of extraction which may minimize delay in head compression and strain on the uterine incision.

\section{METHODS}

Our study includes an analysis of the role of vectis in extraction of fetal head during LSCS in 100 cases of full term pregnancy with 100 controls of manual extraction matched for other variables like age, parity, gestational age, social status and postoperative complications.

The inclusion criteria we considered were-elective and emergency LSCS, singleton pregnancy and cephalic presentation. Women with multiple pregnancy, malpresentations and major degree of placenta previa were excluded.

For all women a detailed history and routine antenatal investigations such as hemoglobin, blood grouping, Rh typing, OGCT, HIV, HBsAg and VDRL were done. The intraoperative techniques used during LSCS were similar in both the groups except for application of vectis in the study group. The instrument used in present study is a specially designed single blade, called murless vectis.
This extractor is a single-blade fenestrated instrument, which at first glance would appear to be a cross between the blade of an ordinary obstetric forceps and a luggage handle. The blade portion is infact similar to the ordinary obstetric outlet blade, except that it possesses an exaggerated cephalic curve. At the base of the blade is a double hinge, thus converting the forceps into a single instrument. The shaft, which connects the blade to the handle, carries a sliding sleeve. When the sleeve is placed into position, it covers the joint and locks the double hinge, thus converting the forceps into a single rigid piece. The break in the shaft accomplished by the double hinge, allows for introducing of the extractor, which would otherwise be impossible, owing to the obstructing pregnant uterus in the anterior abdominal wall ${ }^{5}$. We followed the original Murless technique, which consists of making an initial 2 inch $(5 \mathrm{~cm})$ transverse incision into the lower uterine segment and then inserting the folded extractor between the lower edge of the incision and the fetal head, following which the handle is straightened and the hinge locked. With an assistant holding the extractor to maintain pressure on the fetal head, the head is delivered slowly by continuous traction as the surgeon enlarges the initial uterine incision bit by bit ${ }^{6}$.

Various outcome measures were recorded including time required for extraction of fetus (starting from uterine incision to extraction of head), necessity of fundal pressure, maternal morbidity in terms of extension of uterine incision, hemorrhage due to extension of uterine incision and blood loss attributable to application of vectis. Perinatal outcome such as APGAR, any injuries to the baby during LSCS or presence of hyperbilirubinemia in the baby were noted. Following LSCS, hemoglobin was repeated for all women and the length of abdominal incision was measured (using measuring tape) after 48 hours of surgery.

\section{RESULTS}

Table 1: Time of extraction from uterine incision.

\begin{tabular}{|c|c|c|c|}
\hline $\begin{array}{l}\text { Time } \\
\text { (seconds) }\end{array}$ & $\begin{array}{l}\text { Vectis } \\
\text { group }\end{array}$ & $\begin{array}{l}\text { Conventional } \\
\text { group }\end{array}$ & P-value \\
\hline $15-25 \mathrm{sec}$ & $54(54 \%)$ & $53(53 \%)$ & \multirow{4}{*}{0.390} \\
\hline $26-35 \mathrm{sec}$ & $32(32 \%)$ & $33(33 \%)$ & \\
\hline $36-45 \mathrm{sec}$ & $8(8 \%)$ & $11(11 \%)$ & \\
\hline$>45 \mathrm{sec}$ & $6(6 \%)$ & $3(3 \%)$ & \\
\hline
\end{tabular}

As seen in our study the median age group was 24 years and most of the women ( $85 \%$ in vectis group and $86 \%$ in manual extraction group) belonged to middle socio economic status as per Kuppuswamy classification. There were more number of multigravidae when compared to primigravidae in both the groups, but the difference was not statistically significant. Body mass index for most women in both the groups were in the normal range and all other demographic variables were matched between the two groups. 
Table 2: Fundal pressure.

\begin{tabular}{|llll|}
\hline $\begin{array}{l}\text { Fundal } \\
\text { pressure }\end{array}$ & $\begin{array}{l}\text { Vectis } \\
\text { group }\end{array}$ & $\begin{array}{l}\text { Conventional } \\
\text { group }\end{array}$ & P-value \\
\hline Yes & $0(0 \%)$ & $100(100 \%)$ & $<0.001$ \\
\hline No & $100(100 \%)$ & $0(0 \%)$ & \\
\hline
\end{tabular}

Table 1 show that the time interval between incisions on the lower uterine segment to the extraction of head ranged from $15 \mathrm{sec}$ to $35 \mathrm{sec}$ for majority of women (86\% in vectis group and $88 \%$ in manual extraction group). In vectis group only about $6 \%$ of women and $3 \%$ of cases in manual group required $>45 \mathrm{sec}$. The difference between both the groups was not found to be statistically significant ( $\mathrm{p}$ value 0.390 ).

Table 3: Position of the baby.

\begin{tabular}{|c|c|c|c|}
\hline $\begin{array}{l}\text { Baby } \\
\text { position }\end{array}$ & $\begin{array}{l}\text { Vectis } \\
\text { group }\end{array}$ & $\begin{array}{l}\text { Conventional } \\
\text { group }\end{array}$ & P-value \\
\hline LOA & $9(9 \%)$ & $4(4 \%)$ & \multirow{7}{*}{0.44} \\
\hline LOP & $13(13 \%)$ & $11(11 \%)$ & \\
\hline LOT & $32(32 \%)$ & $62(62 \%)$ & \\
\hline MOBILE & $12(12 \%)$ & $2(2 \%)$ & \\
\hline ROA & $4(4 \%)$ & 0 & \\
\hline ROP & $9(9 \%)$ & $8(8 \%)$ & \\
\hline ROT & $21(21 \%)$ & $13(13 \%)$ & \\
\hline
\end{tabular}

Table 2 demonstrates the following: cases in vectis group did not require any fundal pressure for extraction of head during LSCS whereas all women in the manual extraction group required fundal pressure which gave a significant $\mathrm{p}$ value of $<0.001$. Extension of angle of uterine incision in the lower segment of uterus was found to be $2 \%$ in vectis group and $4 \%$ in the manual extraction group which is not statistically significant (p value 0.717 ).

Table 4: Length of abdominal incision.

\begin{tabular}{|llll|}
\hline $\begin{array}{l}\text { Length of } \\
\text { incision }\end{array}$ & $\begin{array}{l}\text { Vectis } \\
\text { group }\end{array}$ & $\begin{array}{l}\text { Conventional } \\
\text { group }\end{array}$ & P-value \\
\hline$<10 \mathrm{~cm}$ & $22(22 \%)$ & $5(5 \%)$ & \\
\hline $10-12 \mathrm{~cm}$ & $74(74 \%)$ & $68(68 \%)$ & \\
\hline$>12 \mathrm{~cm}$ & $4(4 \%)$ & $27(27 \%)$ & \\
\hline
\end{tabular}

Table 3 shows most of the fetuses were in left occipitotransverse (LOT) position in both vectis $(32 \%)$ and manual extraction group $(62 \%)$. $\mathrm{P}$ value was calculated to be 0.44 which is not significant. Failure of vectis was seen in $6 \%$ cases and was mostly seen in LOT and ROP position. Following failure of extraction with vectis, the fetal head was extracted by manual method.

Blood loss in our study, estimated by measuring the preoperative and post-operative hemoglobin, was similar in both the groups ( $\mathrm{p}$ value 0.153 ).
Table 5: Neonatal morbidity.

\begin{tabular}{|llll|}
\hline $\begin{array}{l}\text { Neonatal } \\
\text { morbidity }\end{array}$ & $\begin{array}{l}\text { Vectis } \\
\text { group }\end{array}$ & $\begin{array}{l}\text { Convention } \\
\text { al group }\end{array}$ & $\begin{array}{l}\text { P- } \\
\text { value }\end{array}$ \\
\hline Apgar & $97(97 \%)$ & $96(96 \%)$ & 0.303 \\
\hline 8 and 9 & $3(3 \%)$ & $4(4 \%)$ & \\
\hline$<8$ and 9 & & & \\
\hline Lacerations & $1(1 \%)$ & $0(0 \%)$ & 0.513 \\
\hline Present & $99(99 \%)$ & $100(100 \%)$ & \\
\hline Absent & & & \\
\hline Hyperbilirubinemia & $6(6 \%)$ & $4(4 \%)$ & 0.124 \\
\hline Present & $94(94 \%)$ & $96(96 \%)$ & \\
\hline Absent & & & \\
\hline
\end{tabular}

Table 4 denotes majority (96\%) of women in vectis group needed a smaller incision of $<12 \mathrm{cms}$ whereas $27 \%$ women in manual extraction group required an incision $>12 \mathrm{cms}$, hence abdominal incision was significantly smaller in the vectis group ( $\mathrm{p}$ value $<0.001$ ).

In Table 5, there was $1 \%$ neonatal injury to the new-born babies in vectis group and no injuries were recorded in manual extraction group. However, the difference noted was not significant ( $\mathrm{p}$ value 0.513). Hyperbilirubinemia was present in $6 \%$ of babies in vectis and $4 \%$ of babies in manual extraction group; $\mathrm{p}$ value was again not significant (0.124).

\section{DISCUSSION}

Ours was a prospective study, which aimed at clinical evaluation of specially designed single blade obstetrics forceps (vectis) over manual method of extraction of fetal head during LSCS. Fetal head extraction is difficult in 1$2 \%$ of cesarean deliveries. ${ }^{7}$ Causes include an impacted fetal head, floating fetal head, extremely low birth weight fetus and breech or transverse fetal lie.

Delivery of floating fetal head, poses real challenge even to an experienced obstetrician where the head has to be brought down to the level of uterine incision - a distance anything from 2.5 to $5 \mathrm{~cm}$ and there is nothing to hold on to on the head (except perhaps the baby's tiny ears!). Besides, being mobile, any attempt at manipulation is associated with the possibility of pushing it further up or to one side. Different measures such as allowing the fluid to drain till the head gets fixed at the incision site, use of fundal pressure by assistants/anesthesiologists, and use of forceps/vectis are undertaken to facilitate extraction of head. ${ }^{1}$ In modern obstetrics many changes have occurred in terms of delivery of fetal head during LSCS, minimizing the risks of extension of angle of uterine incision.

Since there are very limited studies done on this special instrument - murless vectis, the results of present study is compared with results of manual extraction with application of other instruments like ventouse and forceps for extraction of fetal head during LSCS. 
In the study done by Hadalagi NM, Rashmi MB at RIMS Raichur, the role of vacuum application during caesarean section for extraction of floating head was assessed. ${ }^{8}$ The mean incision-delivery (I-D) interval in vacuum group was 44.46 seconds whereas the mean incision-delivery interval in conventional method was 21.84 seconds which was significantly lesser than vacuum group ( $p$ value: 0.00 ). In our present study, the I-D interval was 15-25 seconds in both the groups ( $p$ value 0.390 ).

In the study done by Hadalagi NM, Rashmi MB, the need for fundal pressure was recorded. ${ }^{8}$ All fifty cases in conventional method needed fundal pressure whereas only 12 cases in vacuum group required fundal pressure for the extraction of fetal head. Whereas in our study, vectis group did not need any fundal pressure for extraction, however, all women in manual extraction group required fundal pressure for extraction of head ( $p$ value: $<0.001)$.

In other studies, extension of angle was noted in only one case among vacuum group but no extension of angle was noted in conventional group. ${ }^{8,9}$ The extension in vacuum group might be due to improper application of vacuum and improper skills. In contrast to this study, we found extension of angle of uterine incision was more in manual extraction group (4\% vs $2 \%$ in vectis group). However, this difference was not statistically significant ( $p$ value 0.717).

In one of the recent studies, mild postpartum haemorrhage was noted in two cases of vacuum group and the $p$ value was 0.315 which is not significant. ${ }^{8}$ In the present study we did not have significant blood loss in both the groups ( $p$ value 0.153 ). In our study, length of abdominal incision was significantly less in vectis group. However, it was not translated into decreased postoperative pain. We did not find any studies in the literature for us to compare this aspect of the study.

In other similar studies, neonatal outcomes were measured and no neonatal injuries including soft tissue injury was recorded. ${ }^{8,9}$ Serum bilirubin levels were measured on fifth postnatal day in both groups and there was no statistical difference noted. Similarly, in our study we didn't find significant neonatal injury or hyperbilirubinemia in vectis group compared to manual extraction group.

\section{CONCLUSION}

The use of murless vectis has demonstrated to be more efficacious in terms of reducing maternal discomfort caused due to fundal pressure and in requiring a much smaller abdominal incision combined with insignificant differences in neonatal and other maternal outcomes when compared to manual method of extraction of fetal head during LSCS. However, the instrument requires routine use and improvisation for better application along with more number of studies with a large sample size.

\section{ACKNOWLEDGMENTS}

I would like to thank Dr $\mathrm{N}$ Venkatesh, Consultant obstetrician and gynaecologist, for providing our institution with this priceless instrument, the murless vectis, and for his continued support through the entire time frame of our study.

\section{Funding: No funding sources}

Conflict of interest: None declared

Ethical approval: The study was approved by the Institutional Ethics Committee

\section{REFERENCES}

1. de Rezende J. Cesarean sections, perfecting the technique and standardizing the practice: an analysis of the book Obstetrícia. 2016;23(1).

2. Nargolkar SM. Hay's forceps, Penham, Manila, Philippines. pp. 218-230, 1991.

3. Studd J. Progress in obstetrics and Gynecology, first edition. 2000;8:107.

4. Barton's forceps: An effective aid in cesarean deliveries by John W Larsen Jr MD, Melissa Brunner MD, Sarah Gloria Obican. 2011.

5. Ackerknecht, Erwin H. A Short History of Medicine, Baltimore: The Johns Hopkins University Press, 1982.

6. Bryan C. Murless, Lower Segment Cesarean Section-A New Head Extractor: British Medical Journal. 1948.

7. Levy R, Chernomoretz T, Appelman Z, Levin D, Hagay ZJ. Head pushing versus reverse breech extraction in cases of impacted fetal head during Cesarean section. Eur J Obstet Gynecol Reprod Biol. 2005;121(1):24-6.

8. Hadalagi NM, Rashmi MB. Comparative study of ventouse versus conventional method for extraction of floating head during lower segment caesarean section. Jour Resea Obstet Gynec Infert. 2015;1(1):5-8.

9. Bellad MB, Koli P. Is Vacuum - assisted Delivery a Safer Option for Delivering a Floating Head at Cesarean Section? Jour Perinat Neona care. 2011;12(2):51-3.

Cite this article as: Priyanka HK, Yeddala M, Vimala KR, Shailaja N, Bhat BS, Krishna L. Comparative study of vectis versus manual method for extraction of fetal head during lower segment cesarean section. Int J Reprod Contracept Obstet Gynecol 2017;6:34-7. 